\section{OD TELEMARKA DO KARVINGA}

\section{FROM TELEMARK TO CARVING}

\section{SAŽETAK}

Skijanje spada u specifične ciklične sportove koji u sebi sadrži učenje, usavršavanje $i$ realizaciju različitih motornih veština, radnji $i$ kao takav je tesno povezan sa snežnim površinama na većim nadmorskim visinama. Ne zna se tačno kada je skijanje nastalo, ali zna se da ima bogat $i$ sveobuhvatan istorijski razvoj, kako u delu opreme tako $i$ u delu tehnike. Prve skije datiraju još iz perioda ledenog doba 4500. g.p.n.e. $i$ bile su različitih dužina, teške i široke. Koristio se samo jedan štap. Telemark i Kristijanija bile su osnovne skijaške tehnike skretanja i zaustavljanja skijaša koje se evidentno $i$ dan danas razvijaju $i$ usavršavaju. Položaj, stav $i$ pozicija skijaša doživeli su promene $i$ usko su vezani za dizajn skija i prateću opremu. Dugačke skije različitih dužina zamenile su dve kraće skije istih dužina, savremeni automatski vezovi, dublje i tvrđe cipele i dva kraća identična štapa. Takmičarsko skijanje razvijalo se $i$ menjalo $u$ skladu sa zahtevima takmičenja (tehnika zavoja, dužina i radijus skija, oblik, veličina, broj i međusobni razmak štapova za kapije, kvalitet podloge, visinska razlika staze, itd.). Kratku, tešku i tvrdu skiju zamenile su šezdesetih godina uže $i$ duže skije, da bi devedesetih njih ponovo zamenila kraća, ali lakša $i$ šira karving skija. Novi tehnološki izazovi skiindustrije vezuju se ponovo za užu, lakšu i bržu skiju, ali $i$ za kombinaciju kraće $i$ duže skije u obuci početnika. Dakle, istraživanje se bavi istorijskim predstavljanjem dosadašnjih tehnika $i$ stručne prakse u skijanju, ali i predviđanjima budućih trendova u razvoju alpskog skijanja.
Nikola Stojanović ${ }^{1}$, Zvezdan Savić ${ }^{1}$, Vlado Stijepović $^{2}$ i Ljubiša Lilić $^{3}$

${ }^{1}$ Fakultet sporta i fizičkog vaspitanja, Univerzitet u Nišu,

Srbija

${ }^{2}$ Srpsko Udruženje Učitelja i

Trenera Sportova na Snegu, Beograd, Srbija

${ }^{3}$ Fakultet za sport i fizičko vaspitanje, Leposavić, Srbija

Pregledni članak doi:10.5550/sgia.171301.se.SSSL UDK: 796.92

Primljeno: 05.06.2017. Odobreno: 03.07.2017.

Korespodencija:

Doc. dr Nikola Stojanović, Univerzitet u Nišu

Fakultet sporta i fizičkog vaspitanja Čarnojevića 10a

Niš, 18000

Srbija

$\underline{\text { www.fsfv.ni.ac.rs }}$

Sportlogia 2017, 13 (1), 68-75.

Ključne reči: skijanje, trendovi, skija, tehnika, razvoj 


\section{UVOD}

Nastanak skijanja vezuje se za prostore današnje Norveške. Poznato je da su drevni lovci još pre oko 4500 hiljada godina koristili dugačke i teške skije koje bi im olakšale kretanje kroz neprohodne, snegom prekrivene predele (Lund, 1996). Ovaj period vezuje se za nastanak većih društvenih zajednica kao posledicu trajnog nastanjivanja ljudi, u predelima koji su im pružali mogućnost da eksperimentišu sa kultivisanjem različitih biljnih kultura, koje su kasnije bile sastavni deo svakodnevne ishrane. Formiranje trajnih naselja omogućilo je ljudima da neguju i prošire veštinu upotreba skija u različite svrhe. Ne može se sa sigurnošću konstatovati da li su ljudi u ovom periodu koristili skije za spuštanje niz padinu, ali svakako, njihova upotreba je bila sve učestalija. Međutim, svakako se ne može tvrditi da se ovom ranom periodu može pripisati početak skijanja. Skijanje, u punom smislu te reči, nastaje znatno kasnije i staro je tek oko hiljadu godina. Vezuje se za Vikinškog kralja Haralda Hadradea (1046-1066), koji je veštinu brzog skijanja promovisao kao zabavnu aktivnost u cilju pobede i dokazivanja fizičkih sposobnosti. „Norveško“ skijanje je doživelo svoju punu ekspanziju zaslugom planinskih farmera, odnosno prvih Telemark skijaša u dolini Telemark, 80 kilometara od Osla. Švedski biskup Olaus Magnis 1555. godine izdaje knjigu „Istorija severnih naroda” u kojoj opisuje korištenje skija u lovu, kao i u takmičenju za nagrade. Najzaslužniji za afirmaciju Telemark skijanja bio je Sondre Norheim (Lund, 1996). Njegova najveća zasluga ogleda se u revolucinarnom pronalasku koji je preteča današnjeg Telemark veza. Iako su se i do tada koristili različiti materijali za pričvršćivanje stopala skijaša za skiju, razlika je bila u tome što je Norheim vez napravio od protkanog elastičnog korenja drveta. Ovo je doprinelo boljem pričvršćivanju stopala za skiju, što je neposredno uticalo na razvoj specifičnih tehnika skijanja, kasnije nazvanih Telemark i Kristijanija (Kotnik, 2007). U predelima srednje Evrope, skijanje se prvi put spominje u knjizi istoričara Johana Vajkarta Valvasora „Slava vojvodstva Kranjskog“ iz 1689. Godine (Kotnik, 2007; Živanović, Savić, Milojević, i Milutinović, 2003). U knjizi se opisuju slovenački seljaci na području masiva Bloke, koji se skijama koriste isključivo za kretanje po planinama, te se time oni smatraju prvim skijašima na području srednje Evrope (Živanović, Savić, Milojević, i Milutinović, 2003). Pojavom karving skijaške tehnike razvoj skijanja je doživeo svoju punu ekspanziju, naročito sa stanovišta sa kog se gotovo u potpunosti brišu razlike između rekreativnog i takmičarskog skijanja. Karving skijaška tehnika je takmičarima i rekreativcima omogućila stabilno i brže skijanje na rubnicima skija. Sredinom devedesetih, tačnije 1997. godine napravljen je novi model ,karving“ skije, čija se geometrija zadržala i do današnjih dana. Pojava karving skije, omogućava skijašu opisivanje skijama tačnog, preciznog zavoja, oštrog i jasnog traga. Činjenica je da su, kratku, tešku i tvrdu skiju šezdesetih godina zamenile uže i duže skije, da bi devedesetih njih ponovo zamenila kraća, ali lakša i šira karving skija. Novi tehnološki izazovi ski-industrije vezuju se ponovo za užu, lakšu i bržu skiju, ali i za kombinaciju kraće i duže skije u obuci početnika. Cilj ovog rada bio je da se istorijskom metodom analizira dosadašnja skijaška praksa koja je direktno inicirala nove trendove u razvoju alpskog skijanja. 


\section{METODE}

Istorijska metoda predstavlja osnovnu metodu korištenu $\mathrm{u}$ istraživanju $\mathrm{u}$ istorijskoj metodologiji, koja se, prvenstveno, koristi u istorijskoj nauci. Pored toga, ova metoda može da se primeni u istraživanjima društvenih i prirodnih nauka i kao takva bi mogla da se primeni kao jedna od osnovnih metoda u istoriji fizičke kulture (Savić, 2016). U radu je pored istorijske primenjena i deskriptivna metoda.

\section{DISKUSIJA}

Nove tehnike skijanja, naročito na takmičenjima, uslovljene su promenom materijala od kojih se skija izrađivala. Evolucijom tehnike aplskog skijanja, povećali su se i zahtevi prema proizvođačima ski opreme da obezbede što bolju vezu između skija i skijaša. Skijanje kao takmičarski sport počelo se razvijati znatno kasnije. Prvo takmičenje u skijaškom trčanju i spustu održano je u Kristijaniji (današnji Oslo), gde je osnovan i prvi skijaški klub. Povodom tog takmičenja napisana su i prva skijaška pravila 1767. godine. Razvoju takmičarskog skijanja uveliko je doprinela pokrajina Telemark u Norveškoj. Upravo tamo, braća Nordhajm krajem XIX veka menjaju oblik skija i veza. Prednji i zadnji deo skije postaje nešto širi, a klizavoj ploči se dodaju uzdužni plitki žljebovi koji olakšavaju održavanje pravca skija. Takođe su uvežbali tehniku skretanja i zaustavljanja, što je olakšalo kretanje na skijama. Slalomska tehnika skijanja, odnosno skijanje sa preprekama - štapovima na stazi, počinje se voziti krajem XIX veka, a demonstrirao ga je prvi Arnold Lun. Sam Lun nije sebi prepisivao zasluge, već je tvorcem ove ideje smatrao Kofilda, ali je ujedno bio i oprezan da ne umanji uticaj Zdarskog, koji je bio pionir u kreiranju prve tehnike zaokreta i Šnajdera koji je usavršio (Lunn, 1940). Hanes Šnajder se smatra tvorcem revolucionarne „Arlberg“ metode, koja je predstavljala prvu sistematizovanu metodu obuke skijanja, od plužnog do paralelnog zavoja (Corrocher i Guerzoni, 2009). Pored slaloma, veoma popularna disciplina bila je i spust (downhill). Najpopularnija među njima bio je „Čelendž Kup“ Roberta od Kandahara, a ime je dobio po poznatom Britanskom vojskovođi Frederiku Robertsu, koji je predvodio veliki marš u Avganistanu od Kabula do Kandahara (Kennedy i Nicholls, 1981). Interesantna je činjenica da se Roberts nikada nije bavio skijanjem, niti je bio na Alpima. Objašnjenje se može pronaći u tadašnjem velikom Viktorijanskom patriotizmu. Popularizaciji alpskog skijanja značajno je doprineo i čuveni engleski pisac ser Artur Konan Dojl, kreator lika ekscentričnog detektiva Šerloka Holmsa. On je 1894. godine obavio prelaz od Aroze do Davosa i to ovekovečio duhovitim člankom u Strand Magazinu, što se može smatrati prvom novinarskom reportažom o skijanju (Carr, 1975). Takmičenja se počinju održavati na uređenim terenima, a ocenjuje se isključivo lepota skijanja. Početkom XX veka na stazu se stavljaju veštačke prepreke koje su malo nakon toga zamenjene štapovima sa zastavicama (kasnije zglobni štapovi). Nešto kasnije, dolazi do nove izmene oblika kapija koji se zadržava sve do danas i donosi zajednički naziv ovoj disciplini - slalom. Time se promenio i sam način ocenjivanja. Više se nije ocenjivala lepota vožnje, već brzina prolaska kroz stazu. Ova tvrdnja se može potkrepiti činjenicom da se tehnika u disciplini ,slalom“ često menjala. Takođe, jedan od glavnih razloga zbog koga se težilo stalnom usavršavanju tehnike je pojava zglobnih štapova, koji su omogućavali potpuno novi način prolaska kroz kapije (Savić, 2016). Sve ove promene su uslovile tadašnje ski škole da menjaju koncepciju svog razvoja, tj. morali su ih prilagoditi novim trendovima. Sa sve većim brojem takmičara širom Evrope počinju se osnivati i brojne organizacije. Prvi skijaški savezi osnivani su početkom XX veka u Švajcarskoj i 
Nemačkoj, kao i skijaška Unija Centralne Evrope. Prvi međunarodni skijaški kongres održan je u Kristijaniji (Oslo) 1910. godine. Za vreme prvih Zimskih Olimpijskih igara u Šamoniju 1924. godine, osnovan je Međunarodni skijaški savez „Federation internationale de ski“ - FIS2. Arnold Lun je dobio veliku čast da bude glavni organizator prvog FIS šampionata u Murren-u 1931. godine (Holt, 1992). Kada se skijanje sagleda sa aspekta razvoja skijaških tehnika, može se konstatovati da je bilo zastupljeno više različitih, a neke od prepoznatljivih su svakako: Lilienfeldska, Arlberška, Francuska rotaciona, Tehnika sa suprotnim zasukom tela, Avelman, Džet, Prestupna, Karving (Jabučanin i Đurović, 2011). Matijas Zdarski je nordijsko skijanje i skije prilagodio alpskom terenu. Izumeo je adekvatne metalne vezove koji su se svojevremeno nazivali ,lilienfeld vezovi“. Koristio je jedan dugačak štap za odgurivanje i održavanje ravnoteže (Živanović, Savić, Milojević, i Milutinović, 2003). Zdarski se smatra osnivačem „plužne“ tehnike zaokreta. Ova specifična tehnika skijanja naziva se Lilienfeldska. Za Zdarskog se govori da je bio veliki zaljubljenik u skijanje, te da je zbog toga, verovatno, bio prvi i poslednji Austrijanac koji za usluge obučavanja nije zahtevao novčanu nadoknadu (Lund, 1996). Sa druge strane, Georg Bilgeri je usavršio tehniku skijanja, koja je bila „blend“ lilienfeldske i nordijske tehnike, prilagođene alpskim terenima (Živanović, Savić, Milojević, i Milutinović, 2003). Za razliku od Zdarskog, Bilgeri je umesto jednog, koristio dva štapa radi povećanja stabilnosti skijaša. Takođe, usavršio je lilienfeldske vezove, čime je omogućio usavršavanje dotadašnje tehnike skijanja. Hanes Šnajder je bio prvi profesionalni učitelj skijanja koga se smatra tvorcem „revolucionarne“ arlberške tehnike. Osnovu ove tehnike skijanja činili su plužni zaokret, plužna i škarasta kristijanija i paralelni zavoj. Ono što je Šnajdera izdvajalo od ostalih njegovih prethodnika i savremenika, je uvođenje sistematizovane i metodične obuke u savladavanju skijaških tehnika. On je obuku uslovno podelio na međusobno povezane celine, gde su se određeni elementi skijaške tehnike savladavali po principu „uzlazne piramide“, odnosno od jednostavnijih do složenijih. Osnovni cilj ovakvog pristupa bio je brže i efikasnije savladavanje skijaških tehnika, čime je vremenski period obuke znatno skraćen. Pored toga, efikasnost i ekonomičnost pokreta, karakterističnih za arlberšku tehniku, omogućila je povećanje brzine skijanja, što je bilo naročito važno za razvoj takmičarskog skijanja. Međutim, francuska škola skijanja na čelu sa Emilom Aleom je osporavala arlberšku, smatrajući suvišnim da zaokret treba počinjati i završavati plugom. Smatrali su da bi skijaš iz smuka pravo i koso trebalo da otkliže, i zasukom tela prema padini, promeni pravac kretanja. Takođe, karakteristično za ovu tehniku, težište je pomereno prema vrhovima skija, a prilikom promene pravca kretanja popušta se pritisak na zadnjem delu skija, tako da pokret podseća na šutiranje (ruade) (Guido, 1982; Živanović, Savić, Milojević, i Milutinović, 2003). Mešanjem francuske i austrijske škole skijanja, utemeljena je tehnika koja je sve više podsećala na savremenu, a njen osnivač je bio Stefan Kruckenhauser iz Kitzbühel-a. Svoju inovaciju predstavio je na Međunarodnom kongresu skijaške didaktike „Interski“ 1955. godine, u Valdizeru (Val d'Isère) (Guido, 1982). Prihvaćena je činjenica, da je zasuk tela u pravcu izvođenja zaokreta nepraktičan i da bi ga trebalo zameniti zasukom tela suprotnim od pravca kretanja skija i nogu, čime je omogućen ravnomerniji pritisak dužinom cele skije, kao i veća stabilnost prilikom izvođenja zaokreta. Skijaška oprema je takođe doživela određene promene. Najraniji vezovi u alpskom skijanju nisu omogućavali oslobađanje cipele prilikom padova (Ettlinger i Johnson, 1982). 20-ih i 30-ih godina XX veka, cipela je bila vezivana za skiju uz pomoć dugačkog kabla ili kožnog kaiša, pri čemu je skijašu bila omogućena bolja kontrola skije, ali je zbog nemogućnosti oslobađanja cipele od skije povećan rizik za nastajanje povreda prilikom pada ili različitih situacija u zavoju, pri kojima se povećava uticaj sile na koštano-zglobne strukture (Shealy, Geyer, i Hayden, 1974). U narednim godinama 
osmišljen je vez koji je imao sposobnost oslobađanja pete, ali ne i prstiju. Tek nakon 1950. godine, napravljen je prvi vez sa oslobađajućim mehanizmom, po čijem principu funkcionišu i savremeni (Natri, Beynnon, Ettlinger, Johnson, i Shealy, 1999). Zbog velike težnje za što efikasnijim i bržim skijanjem tehnologija proizvodnje skijaških vezova je konstantno napredovala, dok je konstrukcija skije ostala relativno nepromenjena. Tek je veća ekspanzija ski centara i izgradnja većeg broja ski liftova inspirisala niz novih pronalazaka u dizajnu skija. Najinovativnija ideja je bila postavljanje čeličnih rubnika od strane nepoznatog Austrijskog metalca 1928. Godine (Corrocher i Guerzoni, 2009), odnosno Herija Osvalda Kara 1932. godine, prema patentnoj dokumetaciji (Carr, 1932), što je značajno doprinelo razvoju skijaške tehnike. Povećanjem brzine skijanja, skije koje su bile izrađene od jednog komada drveta, nisu mogle da odgovore novim zahtevima. Proizvodnja kompleksne višeslojne (,laminantne") skije 1939. godine, paralelno sa pronalaskom efikasnijih lepkova, omogućila je veću otpornost na torzione sile, čime se povećala efikasnost zavoja pri većim brzinama. Do 1951. godine, 90\% proizvedenih skija su bile „laminantne“ (Clark, 1985). Haurd Hed je 1954. godine patentirao skiju od kompozitnog drveta i metala, sa plastičnom podlogom, čime je doprineo razvoju proizvodnje skije od „fiberglasa“ (Head, 1954), koje su karakteristične po svojoj otpornosti i značajno manjoj vibraciji pri velikim brzinama. Do kraja šezdesetih godina XX veka skije od „fiberglasa“ su gotovo u potpunosti zamenile „metalne“. Kompanija „Salomon“ 1990. godine je javnosti predstavila skiju sa jednodelnom plastičnom „kapom“ na vrhu i bočnim stranama (Diard i Guers, 1990). U ovom periodu skije su bile dugačke od 175 do 210 centimetara, a njihova širina je bila istovetna duž cele skije. Veoma važan proboj u dizajnu skije, ostvarile su kompanije „Kneissl“ i „Elan“, konstruisavši prototip moderne „karving“ skije početkom 1990. godine. Zbog svojih širokih ,,vrhova“ i ,repova“ i uskog ,struka“ i dužine svega od 160 do 180 centimetara, ove skije su prvenstveno konstruisane za početnike, jer su pružale mogućnost lakšeg zaokreta prilikom postavljanja na rubnik. Ubrzo su i takmičari uvideli da se ovom skijom mnogo lakše upravlja nego tradicionalnom, a da je pritom i stabilnija prilikom izvođenja zaokreta pri većim brzinama. Nova ,karving“ skija se vrlo brzo probila na tržište i postala je standard svim proizvođačima ski opreme (Corrocher i Guerzoni, 2009). U 2002. godini gotovo 100 procenata prodatih skija na tržištu bile su ,karving“ skije (Corrocher i Guerzoni, 2009). Kadase problem sagleda kroz prizmu takmičarskog i rekreativnog skijanja, gde takmičari teže da stazu izvezu u maksimalnoj mogućoj brzini, u idealnoj - najkraćoj putanji, što je tečnije moguće, bez velikog napora i naprezanja, nedvosmisleno se može konstatovati da je moderna „karving“ skija odgovorila postavljenim zahtevima. Čitava istorija alpskog skijanja tekla je u pravcu promene i unapređenja tehnike sa promenom skijaške opreme. Težilo se tome da se takmičaru omogući maksimalna brzina, rekreativcu potpuna sigurnost, tj. prijatno i brzo savladavalje, a samim tim i maksimalno uživanje u snežnim padinama uz jednostavan, lako prihvatljiv put sticanja veštine skijanja. Karving skija je specifičnog izgleda, drugačije geometrije u odnosu na tradicionalnu skiju, šira je i znatno je manje dužine. Sa ovim značajnim izmenama bilo je lakše skijati i manevrisati, tako da je obuka budućih skijaša prilagođena novoj geometriji skije, a skijaši su prinuđeni da se brže i na što efikasniji način prilagode novonastalim situacijama prilikom vožnje. Pomoću karving skija danas je i rekreativnim skijašima omogućeno da skijaju približno istom tehnikom kao i takmičari. Naravno, velika je razlika u tehnici izvođenja zavoja, no pravilno izveden zavoj omogućava jedinstven osećaj skijanja. Iako je „prvi“ model „karving“ skija predstavljen 1997. godine (kompanija „Elan“ Begunje, Slovenija), ideja je nastala znatno ranije. Pregledom patentne dokumetacije došlo se do izvesnog patenta koji je odobren 1950. godine (Louis, 1950). Autor naglašava da je osnovna ideja ovog patenta da se skijaš rastereti od konstantog upravljanja 
skijom time što će skija svojom geometrijom omogućiti veći otpor i prijanjanje uz snežnu površinu. Ovo omogućava da skija bude stabilnija prilikom izvođenja zavoja manjeg radiusa u odnosu na konvecionalnu skiju. Takođe, autori Droste i Stortman u svojoj knjizi na slikovit način opisuju ,strukiranu“ telemark skiju, koja se proizvodila sve do 1940. godine. Prema ovim autorima, tvorac prve ,karving“ skije je bio Sondre Norheim, koji je sa svojim radikalnim idejama, bio ispred svog vremena (Corrocher i Guerzoni, 2009; Droste i Strotmann, 2003).

\section{ZAKLJUČAK}

Na kraju, jasno je da je još krajem XIX i početkom XX veka postojao veliki entuzijazam za razvoj skijanja. To je naravno podrazumevalo da se razvojem skijaških tehnika, čiji su pioniri bili Sondre Norhaim, Matijas Zdarski, Arnold Lun i Hanes Šnadjer, paralelno morala razvijati i ski industrija, bez koje skijanje kao sport i rekreacija velikog broja ljudi, sigurno ne bi bilo gde je sad. Konstrukcija prvog telemark veza obezbedila je jedinstvo tela skijaša i skije, čime je postignuta veća stabilnost i prvi preduslov za neposredni razvoj skijaške tehnike. Pronalaskom veza sa oslobađajućim mehanizmom, smanjen je rizik od povređivanja. Takođe, skija je pretrpela velike promene, od skija izrađenih od jednog komada drveta, do onih izrađenenih od različitih kompozitnih materijala, što je doprinelo većoj stabilnosti i manjoj vibraciji skije prilikom izvođenja zaokreta pri velikoj brzini. Pojavom „karving“ skije na tržištu, skijanje je doživelo pravu revoluciju. „Karving“ skije su skijašu omogućile bolju kontrolu zaokreta u različitim uslovima i brzini izvođenja pokreta. Sa druge strane, obuka početnika je znatno skraćena i olakšana, tako da gotovo svako može da savlada i izvede „karving“ zaokret, što doprinosi većem uživanju skijaša, a samim tim i skijanje sve više dobija na popularnosti. Skijaši u alpskim disciplinama dostižu veliku brzinu kretanja na različitim terenima što zahteva brzo i snažno prilagođavanje. Sem toga skije imaju ulogu poluge, koje u najboljem smislu mogu predstavljati produžetak mišićno-skeletnog sistema poluga tela, a u najgorem, mehanizam koji može izazvati brojne sportske povrede. Pretpostavlja se da će se budući trendovi kretati u smeru proizvodnje što efikasnije i pre svega ekonomičnije opreme, čime će skijanje verovatno dobiti nove poklonike. Rekavši prethodno, nameće se pretpostavka da će skija biti uža, lakša i brža, što će nedvosmisleno doprineti boljim takmičarskim rezultatima, ali i omogućiti rekreativcima veće uživanje u skijanju.

\section{LITERATURA}

Carr, H. O. (1932). Improvements in and relating to skis. Great Britain.

Carr, J. D. (1975). The Life of Sir Arthur Conan Doyle. Vintage Books USA.

Clark, K. B. (1985). The interaction of design hierarchies and market concepts in technological evolution. Research Policy, 14(5), 235-251. https://doi.org/10.1016/0048-7333(85)90007-1

Corrocher, N., \& Guerzoni, M. (2009). Product variety and price strategy in the ski manufacturing industry. Journal of Evolutionary Economics, 19(4), 471-486. https://doi.org/10.1007/s00191-009-0145-9

Diard, J. L., \& Guers, F. (1990). Ski having a variable width upper surface. Google Patents. Retrieved from https://www.google.com/patents/US4953884

Droste, P., \& Strotmann, R. (2003). Telemark Skiing. Meyer \& Meyer Sport. Retrieved from https://books.google.rs/books?id=vTxCiz53okcC

Ettlinger, C., \& Johnson, R. (1982). The state of the art in preventing equipment-related alpine ski injuries. Clin Sports Med, 1, 199-207. 
PMid:7187305

Guido, O. (1982). Knjiga o skijanju. Sarajevo, BIH: "Svijetlost."

Head, H. (1954). Composite wood and metal ski having plastic running surface. Google Patents.

Retrieved from https://www.google.com/patents/US2694580

Holt, R. (1992). An englishman in the Alps: Arnold Lunn, amateurism and the invention of alpine ski racingTitle. The International Journal of the History of Sport, 9(3), 421-432. https://doi.org/10.1080/09523369208713804

Jabučanin, B., \& Đurović, Đ. (2011). Evolucija razvoja smučanja i smučarskih tehnika. Sport Mont, 25, 9-16.

Kennedy, P. M., \& Nicholls, A. J. (1981). Nationalist and racialist movements in Britain and Germany before 1914. Springer.

https://doi.org/10.1007/978-1-349-04958-5

Kotnik, V. (2007). Skiing nation: Towards an anthropology of Slovenia's national sport. Studies in Ethnicity and Nationalism, 7(2), 56-78. https://doi.org/10.1111/j.1754-9469.2007.tb00118.x

Louis, B. (1950). Ski having concave sides. Google Patents. Retrieved from https://www.google.com/patents/US2510794

Lund, M. (1996). A short history of alpine skiing: From telemark to today. Ski Heritage Journal, 5-19.

Lunn, A. (1940). Come what may: an autobiography. Eyre \& Spottiswoode.

Natri, A., Beynnon, B. D., Ettlinger, C. F., Johnson, R. J., \& Shealy, J. E. (1999). Alpine ski bindings and injuries. Current findings. Sports Medicine. Retrived from https://doi.org/10.2165/00007256199928010-00004

Shealy, J. E., Geyer, L. H., \& Hayden, R. (1974). Epidemiology of ski injuries: effect of method of skill acquisition and release binding accident rates. Hum Factors, 16, 459-473. https://doi.org/10.1177/001872087401600504

PMid:4442893

Živanović, N., Savić, Z., Milojević, A., \& Milutinović, D (2003). Alpsko skijanje-tehnika, metodika, psihofizička priprema. Niš, RS: Panaoptikum.

PMCid:PMC1738233

Savić, Z. (2016). Istorija fizičke kulture. Niš, RS: Fakultet sporta i fizičkog vaspitanja, Univerzitet u Nišu. 


\section{SUMMARY}

Skiing belongs to the group of specific cyclical sports which include the learning, improvement and realization of different motor skills and activities, and as such is inextricably linked to snow-covered terrain at higher altitudes. The exact time when skiing was first invented is unknown, but what is known is that its development throughout history was complex, both in terms of skiing equipment and in terms of technique. The first skis date back to the ice age, 4500 $B C$, and were of various length, weight and width. Only one ski pole was used. Telemark and Christiania skiing were the basic skiing techniques of turning and stopping which are still being developed and improved to this very day. The position and stances of the skiers have undergone changes and are closely related to ski design and the design of the accompanying equipment. Longer skis of various lengths have been replaced by two shorter skis of the same length, modern automatic buckles, deeper and sturdier ski boots and two shorter identical poles. Competitive skiing has developed and changed in accordance with the requirements of the competition (the carve turns, the length and radius of the skis, their shape, size, the number of and distance between the poles, the quality of the skiing surface, differences in elevation along the ski slope, etc.). A short, heavy and rigid ski was replaced in the 1960 's by a more narrow and longer ski, only to be replaced once again during the 1990's by a shorter, more lightweight and wider carving ski. New technological challenges facing the ski industry are once again bound to the more narrow, lightweight and faster skis, but also to the combination of shorter and longer skis which are used in beginner training. Thus, this research deals with the historical representation of current techniques and professional and technical practices in skiing, but also the predictions of future trends in the development of Alpine skiing.

Key words: skiing, trends, skis, mechanics, development 